\title{
UN NUEVO PLANTEAMIENTO AL CONTENIDO DEL DERECHO AMBIENTAL
}

\author{
A NEW APPROACH TO THE CONTENT OF ENVIRONMENTAL LAW
}

\author{
Roy Cárdenas Velarde ${ }^{1}$ \\ Universidad de San Martín de Porres \\ Lima-Perú \\ https://orcid.org/0000-0002-9594-8253 \\ rcardenasvelarde@gmail.com
}

\section{RESUMEN}

En el presente artículo el autor aborda distintas problemáticas, las cuales requieren urgente atención por parte de los países, la empresa y sociedad civil, teniendo como sustento las distintas columnas escritas para el Diario Oficial El Peruano. En la mayoría de casos, se afirma que las problemáticas son "ambientales"; sin embargo, el autor nos muestra cómo es que estas son, antes que ambientales, de la sociedad. La lucha contra el cambio climático es la lucha contra un amigo invisible, que cada vez nos conecta un sin número de jabs, y llegará el momento que el que solo tocará al referee hacer el conteo.

\section{PALABRAS CLAVES}

Ambiente, Cambio climático, Derecho humano, Problemática ambiental

\begin{abstract}
In this article, the author addresses different problems that require urgent attention from countries, companies and civil society, based on the different columns written for the Official Newspaper El Peruano. In most cases it is stated that the problems are "environmental"; however, the author shows us how these are, before being environmental, society's problems. The fight against climate change is the fight against an invisible friend, who each time connects us with an endless number of jabs, and the time will come when it will only be up to the referee to do the counting.
\end{abstract}

\section{KEYWORDS}

Environment, Climate change, Human rights, Environmental issues

\section{INTRODUCCIÓN}

En el 2006 se publicó "Una verdad incómoda" un documental de Al Gore que debe ser el que más ha dado de que hablar en relación al cambio climático en los últimos años. Ahora bien, si hay algo más preocupante que una verdad incómoda, es una mentira cómoda. A la cual muchos preferimos aferrarnos y vivir engañados.

1 Abogado especializado en Derecho Ambiental y Gestión Pública, con maestría en Derecho Constitucional por la Universidad de San Martín de Porres. Ha realizado estudios de especialización en derecho ambiental en laAmerican University Washington College of Law y en derechos humanos en la Europäische Akademie Otzenhausen. Se ha desarrollado profesionalmente en el Fondo Nacional del Ambiente, FONAM, y la Adjuntía del Medio Ambiente, Servicios Públicos y Pueblos Indígenas de la Defensoría del Pueblo, el Organismo de Evaluación y Fiscalización Ambiental, OEFA y el Ministerio de Transportes y Comunicaciones, MTC. Cuenta con distintas publicaciones en revistas jurídicas nacionales y ha participado como ponente en distintos en cursos y diplomados. 
Entonces, en el presente artículo el autor buscará brindar al lector un panorama de las distintas problemáticas ambientales, que hoy por hoy deben ser atendidos con especial preocupación por parte de los países, las empresas y la sociedad civiles, teniendo en consideración las columnas escritas durante el presente año para el Diario Oficial El Peruano.

En los últimos meses la atención que ha generado la aparición de la COVID-19 es entendible, pero no es el único mal que existe y que nos viene afectando directamente. La lucha contra el cambio climático es la lucha contra un amigo invisible, que cada vez nos conecta un sin número de jabs, y llegará el momento que el que solo tocará al referee hacer el conteo.

Entonces, en las siguientes líneas se abordarán distintos temas y problemáticas ambientales que, a consideración del autor, deben ser conocidos por la sociedad en general. Empecemos.

\section{PROBLEMÁTICAS (AMBIENTALES), MÍAS Y SUYAS}

¿Qué tan suyas son sus problemáticas ambientales? Pareciera ser una pregunta retórica, pero creo que es la interrogante precisa para introducir al lector a este tema. Además de la pregunta, también tendría que citar lo expresado por la Dra. Nicole Bernex en la VI Jornadas de Reflexión Ética, desarrollada en el año 2008 bajo el título: Ética Ambiental y Política Pública.

En aquella ocasión, la Dra. Bernex (2009) señaló: El primer problema que veo es nuestro propio "comodismo", que no queremos reconocer. Ponemos etiquetas como "temas ecológicos" o "ambientales" (p.18) Suena mejor pues nos distancia del problema. El problema es ético, pues es la actitud del hombre la que genera las distorsiones.

Creo que con ello dejo claro el objetivo de este acápite, el cual radica en entender que las problemáticas, para empezar, no son ambientales, son nuestras, problemáticas de la sociedad, mías y suyas.

Estas últimas elecciones han reflejado lo que he señalado en más de una ocasión: que las problemáticas presentes en la selva, la sierra, o la costa, son tanto mías como de los ciudadanos de aquellas regiones. Exigimos de los candidatos propuestas que, en su mayoría, están pensadas en Lima. Y, entonces, ¿dónde queda aquello que se conoce como solidaridad intrageneracional?

Días antes de los últimos comicios electorales, los medios de comunicación mostraban distintas notas sobre el enfrentamiento personal entre los candidatos presidenciales, antes que debates en torno a sus propuestas, $y$, dentro de ellas, las que pretendan implementar para hacer frente a las problemáticas ambientales, perdón, a nuestras problemáticas. Entonces, ¿qué podemos esperar de los comicios electorales del próximo año? Donde elegiremos a los futuros alcaldes y gobernadores regionales.

El 22 de abril del presente año se publicó en el boletín de normas legales del Diario Oficial El Peruano, el Decreto Supremo $N^{\circ}$ 004-2021-JUS, que crea el Mecanismo intersectorial para la protección de las personas defensoras de derechos humanos, con el cual se van dando los primeros pasos para proteger, de manera efectiva, a nuestros defensores ambientales, quienes quizás para usted no sean muy conocidos ya que su lucha y vida no se desarrolló necesariamente en Lima.

Como parte de cualquier comicio electoral, debemos siempre exigir por parte de los candidatos -antes que enfrentamientos mediáticos- propuestas claras y factibles para hacer frente a nuestras problemáticas, dentro de ellas las que se relacionan a nuestra casa, el planeta. 


\section{EL DÍA DE LA SOBRECAPACIDAD}

Cada año que empezamos se inicia un conteo regresivo, el cual termina cuando la humanidad consume todo lo que el planeta nos ofrece en 12 meses. El día exacto en que el conteo se paraliza se ha denominado "Día de la Sobrecapacidad".

El 2021 lo empezamos con ese mismo conteo regresivo, y se esperaba que esa fecha -"Día de la Sobrecapacidad"- demore en llegar. O, por lo menos, más de lo que demoró en el 2020; sin embargo, no fue así.

Para tener una idea, en el 2019 ese conteo terminó el 22 de julio, mientras que en el 2020 terminó el 22 de agosto, esto es casi solo un mes después, y se presumía que ello se debía al contexto de pandemia y las medidas de confinamiento que se dispusieron en el Perú y otros países del mundo por la Covid-19.

En el 2021 ese conteo terminó el 29 de julio, sólo siete días después que la fecha del 2019, año en que el Covid-19 era algo desconocido y la humanidad vivía sus días de lo más normal.

Lo antes mencionado evidencia que el ritmo de consumo de la humanidad ha vuelto a ser el de antes de la aparición de la Covid-19 en el 2020, incluso podríamos decir que se ha acelerado, ya que en los primeros meses del 2021 algunos países aún mantenían medidas de confinamiento o restricciones al tránsito de personas, debido a la alerta por el brote de una segunda o, en algunos países, tercera ola.

Queda claro entonces que, en un contexto de no pandemia, y con el actual ritmo de consumo, dicho conteo hubiese terminado el mismo 22 de julio que se alcanzó en el 2019, o tal vez mucho antes.

Conviene recordarle nuevamente al lector que el desarrollo sostenible se basa en una solidaridad intergeneracional y otra intrageneracional. Esta última es la que hace alusión a nuestros contemporáneos, recordemos que los recursos destinados a satisfacer las necesidades de una región pueden conllevar a que otra se quede sin estos para satisfacer las suyas.

"No es cuánto necesito, sino cuánto tengo para vivir", fue el consejo que alguna vez me dieron mis padres para mis finanzas, y que considero deberíamos aplicar al momento de evaluar el consumo de algún recurso de la naturaleza.

Puede que interiorizando esta frase logremos pagar nuestra deuda eterna con el planeta y, con mayor esfuerzo, asegurar primero, los recursos que permitan a nuestros contemporáneos satisfacer sus necesidades, así como pagar nuestra deuda eterna y, luego, garantizar los recursos para las generaciones futuras.

\section{UNA DEUDA (AMBIENTAL) ETERNA}

Más de uno habrá escuchado la frase "deuda eterna" acuñada en alusión a la deuda externa que asumen los Estados; con lo que se deja entrever que dicho endeudamiento no tiene fin, por más políticas o prioridades adoptadas, es difícil (por no decir imposible) llegar a cubrirlo en su totalidad. 
Ahora bien, existe otra deuda que año tras año asumimos, y no con otros Estados u organismos internacionales, sino con el planeta, lo que nos lleva a vivir a crédito con este. Lo que se convertiría en nuestra deuda ambiental eterna.

Como se indicó, con el inicio de cada nuevo año, comienza también un nuevo conteo que llega a su fin el día en que la humanidad consume todo lo que el planeta nos ofrece en 12 meses. El "Día de la Sobrecapacidad" en el 2020 terminó el 22 de agosto, esto es casi sólo un mes después al del 2019.

Conviene precisar que el Desarrollo Sostenible se basa en una solidaridad intrageneracional y otra intergeneracional. Esta última es la que hace alusión a las generaciones futuras y a su capacidad para satisfacer sus necesidades, y es quizás con la que más nos encontramos familiarizados.

Corresponde precisar que la solidaridad intrageneracional es aquella referida a nuestros contemporáneos. Recordemos que los recursos destinados a satisfacer las necesidades de una región pueden conllevar a que otra se quede sin estos para satisfacer las suyas.

Es por ello que debemos ser conscientes con el uso y consumo de los recursos que nos brinda la naturaleza, sea para consumo directo o indirecto. En el 2020 se postergó sólo por un mes el "Día de la Sobrecapacidad", lo que haría presumir que en un contexto de no pandemia dicha fecha se hubiera alcanzado en el mes de julio, o tal vez antes.

Año tras año consumimos más de lo que debemos. Como comenté, una de las mejores lecciones que me han dado mis padres es: "No es cuánto necesito, sino cuánto tengo para vivir". Considero que deberíamos interiorizar esta frase cuando decidamos consumir algún recurso de la naturaleza. Es como si participáramos en la carrera "Wings for life", que destina lo recaudado para la investigación de lesiones de médula espinal, en la cual gana quien más lejos llegue antes de que un automóvil lo alcance. En ese caso, entre menos consumamos, más lejos vamos a llegar, y es así como ganaremos.

\section{V. $+10,+20$, Y AHORA +50}

Estoy seguro que Río+10 y Río+20 le es familiar. En caso no sea así, descuide. Cuando decimos Río, nos referimos a la Conferencia de las Naciones Unidas sobre el Medio Ambiente y el Desarrollo, celebrada en 1992 en Río de Janeiro, Brasil.

En octubre, la Asamblea General de las Naciones Unidas acordó celebrar durante la semana del Día Mundial del Medio Ambiente del próximo año, una reunión internacional del más alto nivel posible en Estocolmo, en conmemoración a la Conferencia de las Naciones Unidas sobre el Medio Humano, celebrada en 1972 en dicha ciudad de sueca. Entonces, ahora nos referiremos a este evento como Estocolmo+50.

Pero, ¿por qué sumamos y no restamos? Sería más "vendedor" colocar un valor positivo delante de Río o Estocolmo, quizás porque los expertos tendrán periodos más largos sobre los cuales analizar lo bueno y malo o lo que se hizo y lo que no. Sin embargo, debemos cambiar nuestra forma de ver estos eventos.

Quizás podamos tomar como punto de referencia el año 2050, fecha en la que se espera alcanzar la tan anhelada neutralidad climática. Considero que en tanto debemos entender que, así como la 
selección nacional de fútbol está jugando sus últimas opciones para calificar al mundial de Qatar, el mundo se está jugando su último tiempo suplementario.

Dicho evento se realizará bajo el lema "Estocolmo+50: un planeta sano para la prosperidad de todos -nuestra responsabilidad, nuestra oportunidad", y a menos que los representantes de los países convenzan de que sus decisiones son las mejores y oportunas para alejarnos de ese punto de no retorno al cual nos acercamos cada vez más, veremos nuevamente como una adolescente resume sus discursos con un simple "bla bla bla".

Fue también en octubre que una buena noticia llegaba desde Ginebra, y tenía como antecedente más remoto justamente la Declaración de Estocolmo, adoptada en 1972 en la Conferencia de las Naciones Unidas sobre el Medio Humano. Se trata de la Resolución A/HRC/48/L.23/Rev.1 del Consejo de Derechos Humanos de las Naciones Unidas, que reconoce el derecho a un medio ambiente sin riesgos, limpio, saludable y sostenible como un derecho humano importante para el disfrute de los derechos humanos.

Si bien Estocolmo significó el punto de partida para lo que años después fue la consolidación del derecho humano a un ambiente sano, y en ello radica la importancia de su conmemoración, debemos entender que ahora estamos jugando los últimos minutos de nuestro partido contra el cambio climático.

Restar, antes que sumar. Solo así entenderemos que planes a mediano y largo plazo, son lujos que ya no nos podemos dar más. Todo debe ser creado y pensado para ayer.

\section{VI. ¿CÓMO DEJAMOS DE AVANZAR HACIA ATRÁS?}

El pasado 19 de mayo se presentó el informe "BIDeconomics Perú: Oportunidades para la recuperación y el crecimiento sostenible y resiliente", elaborado por el Banco Interamericano de Desarrollo (BID). Un informe que a cualquiera le deja un sinsabor.

Si bien hasta antes de la pandemia el Perú registraba un crecimiento económico, eso no se traducía en un crecimiento social e incluyente, lo cual Santiago Levy Algazi, exvicepresidente de Sectores y Conocimiento del BID, hizo notar durante su participación en dicha presentación.

El recientemente publicado informe contiene un capítulo titulado "Aprovechar la oportunidad para una recuperación verde, sustentable e inclusiva”, en el que primero nos recuerda nuestra lamentable, pero cierta realidad, y luego pasa a desarrollar una serie de propuestas.

Dentro de nuestra lamentable realidad encontramos el hecho de que la degradación ambiental tiene impactos económicos que rondan el $4 \%$ del PIB. También, nos recuerda que la minería es un motor de crecimiento para el país, pero que la sociedad debe convivir con las actividades informales que se desarrollan en dicho rubro. Otro punto, es el de la expansión urbana, la cual se ha caracterizado por la construcción de viviendas informales, haciéndolas vulnerables y poco resilientes.

Dentro de las propuestas que se realizan en el informe, encontramos el reforzar la gestión medioambiental, mejorando la coordinación institucional entre entidades administrativas y la de éstas con las judiciales. También, encontramos la implementación de un plan de mitigación de la minería informal, a través del mapeo de áreas vulnerables, así como movilizar recursos para financiar inversiones sostenibles y resilientes, y la adopción de energías renovables. 
En resumidas cuentas, el haber registrado un crecimiento económico, no garantizó que registremos un crecimiento social e incluyente. Ambos tipos de crecimiento deberían ir de la mano. Es decir, si llueve, nos mojamos todos.

Esto ya lo advertía Zygmunt (2014) en su obra “¿La riqueza de unos pocos beneficia a todos?”, al señalar que ciertos indicadores económicos pueden inducir al error, como es el caso de la renta per cápita. Para eso Bauman hace uso del ejemplo de los pollos y el consumo, esto es, si mi vecino comió 7 pollos a la semana y yo 3 , se puede decir que ambos comemos 5 pollos a la semana, cuando no es necesariamente así.

Debemos buscar la forma de que ese crecimiento económico que el Perú volverá a registrar, superada la pandemia, se sustente en la teoría del goteo. Involucremos a todos los actores y no los hagamos beneficiarios, sino partícipes del desarrollo ambiental y social, cumpliendo un rol activo.

\section{VII, CONTAMINACIÓN, UN TEMA UN POCO SNOB}

A inicios de año se conoció la decisión de un tribunal francés de detener la deportación de un ciudadano de Bangladesh, ya que regresarlo a su país significaría poner en riesgo su vida debido al asma que padecía y a los altos niveles de contaminación en esa nación.

Otro caso que se conoció fue el de Ella Adoo-Kissi-Debrah, una niña de 9 años que falleció en el 2013, y posteriormente, el Tribunal de Investigación de Southwark encontró que la contaminación ambiental -producto del exceso de dióxido de nitrógeno (NO2)- "contribuyó materialmente" a su muerte.

Ambos casos ocurrieron a miles de kilómetros de distancia de nuestro país, pero en algunos años podría ser una noticia lamentable y común en nuestra región. Recordemos que un estudio de Environmental Research, ubica al Perú dentro de los 10 países con mayores proporciones de muertes atribuibles a la contaminación del aire por quema de combustibles fósiles en América Latina.

Todo se agrava ahora que se ha conocido que la Organización Mundial de la Salud (OMS) ha llegado a la conclusión de que la contaminación del aire es más peligrosa de lo que se pensaba.

Dentro de los tipos de contaminantes en la salud humana encontramos: las partículas en suspensión PM2.5 y PM10; el ozono (O3); el monóxido de carbono (CO); el dióxido de azufre (SO2) y el dióxido de nitrógeno (NO2), este último el que habría contribuido a la muerte de Ella Adoo-KissiDebrah.

Según los recientes datos de la OMS, más de 7 millones de personas mueren prematuramente cada año producto de la contaminación del aire. Lo cierto es que, tanto la contaminación del aire exterior como el humo en interiores, representa un grave riesgo para la salud.

Por ello, respecto a la contaminación del aire exterior, se deben adoptar medidas en materia de transporte, planificación urbana, generación de electricidad, industria, gestión de desechos municipales y agrícolas, etc. Por otro lado, respecto al humo en interiores, se deben destinar esfuerzos para que cada vez menos hogares utilicen combustibles sólidos (es decir, madera, residuos agrícolas, etc.) y tecnologías ineficientes, en sus labores diarias. 
Si bien las recientes directivas de la OMS no son vinculantes, lo cierto es que, adoptar esas medidas reducirá el riesgo de sufrir males como: infecciones respiratorias, enfermedades cardiovasculares, accidentes cerebrovasculares, y cáncer de pulmón.

\section{VIII. ¿DEFENSORES O VÍCTIMAS AMBIENTALES?}

Es increíble cómo en tan pocos días podemos pasar de la alegría a la tristeza. Este año celebramos el hecho de que Liz Chicaje, lideresa indígena del pueblo Bora, haya obtenido el premio Goldman 2021, y también nos enteramos del cruel asesinato de Marcos López, líder asháninka y secretario de EcoSira.

Lamentablemente, el asesinato de defensores y defensoras ambientales es una terrible realidad que compartimos con otros países de la región. Tenemos el caso del hermano país de Colombia, uno de los países con la mayor tasa de defensores y defensoras ambientales asesinados, ello lo demuestra un reciente informe de la ONG británica Global Witness.

Un poco más al norte, tenemos el caso de México. En el mes de junio se confirmó el asesinato del líder indígena Tomás Rojo, quien es recordado por encabezar la "guerra por el agua" en el 2010.

Como se puede observar, esta triste realidad no es algo reciente. Es más, no se podría decir que dichos asesinatos son realizados de manera fortuita. En la mayoría de los casos, estos defensores y defensoras ambientales son víctimas de amenazas y actos de hostigamiento, y en algunos otros, sobrevivientes de atentados posteriores.

La hermana del líder indígena Marcos López comentó a Ojo Público que él recibía amenazas desde hace algún tiempo. Agrega Fredy Vásquez, coordinador de campo de EcoSira, que dichas amenazas provendrían de un grupo de narcotraficantes que operan en la zona.

Pero, si ya se sabía de estas amenazas, entonces, ¿qué estamos haciendo mal? Considero que hasta no contar con mecanismos efectivos para proteger a los defensores y defensoras ambientales ante las amenazas o atentados que puedan recibir, la Policía Nacional del Perú debería poner a buen resguardo a estos y estas. El pretender asignarles un resguardo policial las 24 horas del día puede ser inviable, si tomamos en consideración que estas zonas son muchas veces de difícil acceso, y que las dependencias policiales no siempre cuentan con el número adecuado de efectivos.

Ante ello, quizás lo más conveniente sea colocar a los defensores y defensoras ambientales en buen resguardo, incluso trasladarlos a otras zonas mientras duran las investigaciones que permitan dar con los responsables de las amenazas o atentados.

Lo cierto es que ahora queda en manos de la Fiscalía Provincial Mixta de Puerto Bermúdez, Oxapampa, realizar las investigaciones a fin de que formalice denuncia penal contra los autores de tan horrendo crimen, a fin de que no quede impune.

Como se puede ver, una verdad incómoda para parte de la sociedad es qua cada vez el término "defensores ambientales" viene resonando, lo lamentable -la verdad incómoda- es que cada vez más defensores vienen desapareciendo, y algunos mueren en el anonimato. 


\section{DIAGNÓSTICO: ECO-ANSIEDAD}

En setiembre se conocieron los resultados de la encuesta realizada por la Universidad de Bath, a jóvenes de entre 16 y 25 años procedentes de 10 países. Si bien el Perú no estuvo comprendido dentro de esos países, sí lo estuvo Brasil.

De los resultados más penosos, pero justificados, se tiene que el $65 \%$ de los encuestados siente que sus gobiernos les están fallando, mientras que el $83 \%$ indicó que las personas fallaron en cuidar el planeta. Dentro de ese universo de "personas" nos encontramos tanto usted como yo. Duro, pero cierto.

Hoy en día, los jóvenes acceden a información de lo que acontece en cualquier parte del mundo; por lo que, para ellos es fácil conocer sobre las tragedias climáticas como las altas temperaturas, precipitaciones, sequías, migración climática, etc.

Es penoso ser joven hoy en día. Crecer conociendo -si no es que viviendo en carne propia- sobre las tragedias climáticas actuales.

En términos de la Asociación Estadounidense de Psicología, el diagnóstico es claro: todos ellos sufren de eco-ansiedad. Y la culpa de ello es nuestra y de nuestros gobernantes, con la inacción o acción equívoca.

Como parte de la encuesta, se tuvo que el $39 \%$ de los jóvenes duda sobre tener hijos. Entendible. Y más, si a ello le sumamos los resultados del último reporte del Grupo Intergubernamental de Expertos sobre el Cambio Climático.

El crecimiento demográfico es un tema que preocupa, y que considero se debe evaluar cuando hablamos sobre la lucha contra el cambio climático. Toda vez que somos muchos para los recursos que nos provee la naturaleza.

Según Naciones Unidas se prevé que la población mundial alcance los 8.500 millones en 2030. Una cifra que preocupa si tenemos en consideración que en 1950 se estimaba que la población mundial era de 2.600 millones, menos del $50 \%$.

Uno de los factores que trajo abajo la teoría Malthusiana es la producción industrializada de alimentos. Bajo su teoría, la población humana crece según una progresión geométrica, mientras que los recursos del planeta crecen al ritmo de una progresión aritmética, lo que llevaría a un punto en el que no se tendrán suficientes recursos para alimentar a toda la población; sin embargo, la producción industrializada de alimentos ha llevado a que se pueda aprovechar más recursos. Pero eso tiene un costo.

Entonces, como lo he afirmado, dentro del debate sobre las medidas para luchar contra el cambio climático se debe analizar el factor poblacional. Pero, y con esto termino, es penoso e injusto que los jóvenes duden sobre tener hijos no por un tema de consideración hacia el planeta, sino por una preocupación respecto a las peripecias a las que se encontrarán expuestos.

Como alguna vez lo señalé, y creo que esa sería nuestra verdad incómoda, para poder darle un respiro al planeta y que este se puede recuperar, el hombre tiene que dejar de multiplicarse. En ese caso, como se dice en la gestión pública, menos, es más. 


\section{EL COSTO AMBIENTAL DE LA CASA PROPIA EN CIUDADES NADA SOSTENIBLES}

Hoy por hoy existe un proceso en curso ante el Tribunal Constitucional, iniciado por la Municipalidad Distrital de San Isidro contra el Ministerio de Vivienda Construcción y Saneamiento (MVCS) en relación al Decreto Supremo N 002-2020-VIVIENDA, que modifica el Reglamento Especial de Habilitación Urbana y Edificación.

En resumidas cuentas, la polémica radica en que: a la Municipalidad se opone a la construcción de edificios multifamiliares con viviendas más pequeñas, porque ocasionaría que el precio de los inmuebles en su distrito se devalúe, para el MVCS esta norma resulta importante ya que lograría que se construyan más viviendas para las familias peruanas y, finalmente -como señaló José Rubén Velarde, Director de Inversiones Inmobiliarios Credicorp Capital Asset Management-, esto permite mantener el ticket (precio) promedio del departamento, y atenuar el impacto del aumento de precios de las viviendas.

A simple vista, pareciera que lo planteado por el MVCS es un tema de justicia para las familias que no tienen un techo donde vivir, en tanto, pareciera que a las autoridades de la comuna de San Isidro sólo les preocupa el valor de sus inmuebles (del cual depende el pago de ciertos tributos que recaudan), y que las empresas constructoras están preparando limonada con los limones que se les ha brindado.

Al margen de cuál sea la verdad de la milanesa, lo cierto es que para la Organización Mundial de la Salud (OMS) se debería contar con $9 \mathrm{~m}^{2}$ de espacio verde por habitante. Algo que difícilmente se cumple en el Perú, y que medidas como las dispuestas por el MVCS con la aprobación del DS, podrían complicar más aún ese promedio.

De acuerdo con el Ministerio del Ambiente, el distrito de San Isidro es el segundo distrito que tiene mayor superficie de área verde por habitante, pasando de 20.20 en el 2017 a 22.09 en el 2018, sólo por detrás de Santa María del Mar.

Entonces, ¿es válido promover proyectos de edificios multifamiliares en aquellos distritos que aún tienen un "saldo a favor"? Y, lo que preocupa aún más, cuando ya no tengamos dónde más construir viviendas en Lima, ¿a dónde iremos a vivir?

Podemos crecer de manera vertical, corriendo el riesgo de sobrepoblar la ciudad, o de manera horizontal, corriendo el riesgo de afectar ecosistemas frágiles, como se podría dar en el Valle de Lurín. Ambas medidas pueden ser viables, el tema es cómo se plantean y materializan de forma amigable con el ambiente, sino la siguiente pregunta será, ¿de dónde sacamos áreas verdes?

Mientras que otras ciudades apuntan a convertirse en unas 100\% sostenibles, en el Perú, específicamente, en Lima, estamos buscando dónde nos queda sobrepoblar. Una verdad cómoda, es la de creer que Lima tiene que seguir siendo el referente a bienestar y desarrollo, cuando ese bienestar se encuentra en otras partes de país, y en las cuales el Estado tiene que invertir en su desarrollo.

\section{EL DESARROLLO SOSTENIBLE PARA LA GENERACIÓN ACTUAL}

En el acápite titulado "La deuda (ambiental) eterna", se menciona al desarrollo sostenible e indico que este se basa en una solidaridad intrageneracional (respecto a la generación actual) y otra intergeneracional (respecto a las generaciones futuras). 
Al margen de lo manifestado en su momento, considero que es necesario reflexionar sobre lo que significó y sigue significando el desarrollo sostenible.

Haciendo un poco de memoria, se podrá recordar que dicho término fue acuñado por la Comisión Mundial sobre el Medio Ambiente y el Desarrollo en 1987 en el informe "Nuestro Futuro en Común", definiéndolo así: La humanidad tiene la capacidad para lograr un desarrollo sostenible que garantice la satisfacción de las necesidades de la actual generación sin comprometer la calidad de las generaciones futuras para satisfacer las suyas."

Entonces, se tiene que los nacidos a partir de 1987 están dentro de esa generación futura, a la cual se debía garantizar la capacidad de satisfacer sus necesidades. Pero, y esto lo dejo a criterio del lector, ¿considera que cuenta con los recursos para satisfacer sus necesidades?

Al margen de la opinión que pueda merecer, en enero el Programa de las Naciones Unidas para el Medio Ambiente (PNUMA) publicó el Informe sobre la Brecha de Adaptación 2020, donde señala que -sin que ello sea necesariamente una novedad-se prevé que las consecuencias de la Covid-19 influyan considerablemente en la capacidad de los países para planificar, financiar y aplicar medidas de adaptación frente a los efectos del cambio climático.

Claro está, los países más vulnerables (entre ellos, el Perú) seguirán siendo los más perjudicados. Por su parte, Andersen (2021) directora ejecutiva del PNUMA, indicó a la BBC Mundo que con su expresión "no hay una vacuna para el cambio climático", realizada en una conferencia de prensa, pretendió dar a entender que en el caso de la Covid-19 se ha encontrado una solución tecnológica -vacuna- con la cual se pueda llegar al fin de esta historia. Pero no hay una vacuna para el planeta.

A partir de 1987 los estados debían actuar respecto de la población existente en ese entonces, así como de las que vendrían más adelante. Pero, siendo parte de aquella generación (futura), me pregunto, ¿cómo podemos asegurar la capacidad de las generaciones futuras para satisfacer sus necesidades, si actualmente no podemos garantizar las nuestras?

Para la generación actual el desarrollo sostenible debiera ser una realidad, y no un objetivo a alcanzar. El cual se dificulta ya que como mencioné en "La deuda (ambiental) eterna", actualmente estamos viviendo a crédito con el planeta.

\section{ENTRE DESIERTOS Y BOSQUES}

La Organización de las Naciones Unidas (ONU) promueve campañas o asigna lemas a las distintas fechas conmemorativas. Así pues, el pasado 17 de junio se celebró el Día Mundial de Lucha contra la Desertificación y la Sequía y el lema asignado en esa ocasión fue "Restauración. Tierras. Recuperación". Algo no tan sencillo, pero sobre lo cual se vienen adoptando medidas.

En mayo se publicó la Resolución Ministerial № 096 -2021-MINAM, por medio de la cual se aprueba el Plan Nacional de Adaptación al Cambio Climático del Perú: un insumo para la actualización de la Estrategia Nacional ante el Cambio Climático, en el cual podemos encontrar información que resulta importante mencionar al lector, y que se relaciona con la desertificación y sequía.

Primero, nos recuerda que el Perú presenta siete de las nueve características reconocidas por la Convención Marco de la ONU sobre el Cambio Climático (CMNUCC) para calificar a los países 
particularmente vulnerables al cambio climático, dentro de estas, la referida a zonas expuestas a inundaciones, sequías y desertificación.

Segundo, haciendo referencia a la Cuarta Comunicación Nacional del Perú a la Convención de la Naciones Unidas de Lucha contra la Desertificación en los países afectados por Sequía Grave o Desertificación (CNULDS), precisa que el Perú es el tercer país de Sudamérica con mayor extensión de tierras secas (516 $000 \mathrm{~km} 2$ ), y que aproximadamente 30 millones de hectáreas se encuentran en proceso de desertificación y 3,8 millones de hectáreas ya están desertificadas.

Luchar contra la desertificación y sequía resulta importante, tanto desde un plano ambiental, como también económico y social. Pero, además se deben adoptar medidas para la preservación y conservación de bosques.

En relación a lo anterior, se tiene la investigación publicada recientemente en la revista Proceedings of the National Academy of Sciences, la cual estuvo a cargo del Instituto Smithsonian de Investigaciones Tropicales en Balboa, Panamá.

Al respecto, la doctora Piperno (2021) persona responsable de la investigación, comentó a la BBC News que los hallazgos aportan evidencias de que el uso de la selva tropical por parte de la población indígena "fue sostenible, sin causar pérdidas de especies detectables o alteraciones durante milenios".

Entonces, vemos dos temas opuestos, pero que se complementan al momento de hablar sobre la lucha contra el cambio climático.

\section{LA EXTERNALIDAD POSITIVA DE LAS CATÁSTROFES AMBIENTALES}

Hace unos años tuve la oportunidad de llevar un curso en el viejo continente, el cual incluía -como parte del programa- una visita al Campo de concentración de Struthof-Natzweiler. Visitar cada uno de sus ambientes era algo en verdad desgarrador.

Recuerdo que antes de retirarnos del campo de concentración el coordinador del curso, el profesor Joaquín González lbáñez, nos comentó que si bien la historia de Europa está llena de hechos como la Primera y Segunda Guerra Mundial, las cuales concluyeron con la muerte de miles de personas inocentes, ello trajo consigo que hoy se tenga un alto nivel de protección de los derechos humanos, y contar con organismos nacionales e internacionales que velen por el respeto de esos derechos.

Cada vez que recuerdo ello, automáticamente lo relaciono a los temas ambientales y caigo en cuenta -nuevamente- que sucede algo similar. Sin ir muy lejos, tenemos el caso del desastre de la ciudad de Minamata, la cual ha traído como consecuencia que, con los años, se adopte el instrumento internacional que lleva el nombre de dicha ciudad, y que versa sobre el uso de mercurio.

Otro desastre (no tan conocido, tal vez) que resulta importante para lo que ha sido la aparición y expansión del derecho ambiental, es el de 1967, cuando se dio la marea negra en las costas de Francia, Inglaterra y Bélgica, producto del impacto del buque petrolero Torrey Canyon, el cual algunos autores atribuyen como la causa de que en 1972 se haya realizado la Conferencia de las Naciones Unidas sobre Medio Humano, celebrado en la ciudad de Estocolmo, Suecia. 
Y así, podemos seguir enumerando una serie de catástrofes ambientales que, en el corto, mediano o largo plazo, trajeron consigo alguna reacción por parte de los Estados y la sociedad civil. Invito al lector a buscar algunos de ellos, quizás sobre el desastre de Bhopal de 1984, o el derrame de Samarco de 2005.

Ya lo mencionaba la doctora Garrido (2014) en su obra El riesgo ambiental, "(...) lamentablemente, pero los eventos dramáticos generan preocupación y la preocupación genera concientización y acción"

Como se puede ver, los temas ambientales también están llenos de aciertos y desaciertos. Al igual que en el caso de las Guerras Mundiales, estas también trajeron consigo pérdidas humanas.

De una manera fría, y utilizando términos económicos, tenemos que los avances en pro de la defensa del ambiente y, por ende, de la persona, han sido externalidades positivas de hechos catastróficos. Esperemos que en un futuro no se requiera de ellos para generar concientización y acción.

\section{SÓLO TENDREMOS TERCIO AMBIENTE}

Recientemente, Botanic Gardens Conservation International $(\mathrm{BGCl})$ publicó su reporte Estado de los árboles en el mundo, el cual concluye que aproximadamente un tercio y la mitad de las especies de árboles en todo el planeta podrían desaparecer. Entonces, ya no sé si en unos años tendremos $1 / 2$ ambiente, o un tercio.

Lo cierto es que la deforestación constituye un tema que preocupa sobremanera. Recordemos que los bosques son sumideros de carbono, y que a inicios del presente año la WWF publicó su reporte titulado "Frentes de deforestación; impulsores y respuestas en un mundo cambiante", que daba cuenta de 24 lugares altamente amenazados por la deforestación que cubren un área de 710 millones de hectáreas.

Nueve de los 24 lugares amenazados se encuentran en América Latina. Y, sí, el Perú se encuentra comprendido dentro de los países afectados. Pero, ¿qué obligaciones tiene el Perú respecto a la deforestación y, sobre todo, la biodiversidad?

En julio de este año la Organización de las Naciones Unidas publicó una nota en la que se hacía mención a los deberes de los Estados vinculados a los derechos humanos y la biodiversidad, en el marco de distintos instrumentos internacionales, como es el Convenio sobre la Diversidad Biológica. El primero de estos deberes consiste en abordar la pérdida de biodiversidad y hábitat.

En el caso del Perú, dentro de las actividades que ponen en riesgo nuestros bosques y la biodiversidad, tenemos la minería ilegal. El caso más representativo es el de Madre de Dios, conocida como Capital de la Biodiversidad. Exacto, ¿qué biodiversidad? Si ya todo lo viene depredando la minería ilegal.

El 26 y 27 de agosto pasados se realizaron operativos en contra de estas actividades en el sector río Pariamanu, distrito y provincia de Tambopata, departamento de Madre de Dios, donde dicho sea de paso entre el 2017 y mayo de este año se perdieron 204 hectáreas, según el Proyecto Monitoreo de la Amazonía Andina (MAAP). 
Siempre he indicado a mis alumnos que no debemos tener una visión sesgada de la minería ilegal. Esto es, no pensar que la minería ilegal es sólo aquella que se ve en Madre de Dios, sino que ese tipo de actividades se encuentran presentes a nivel nacional. Pero, ahora les diría que, con el fin de tomar conciencia y acciones, pensemos que, si no hacemos algo, otras regiones podrían tener el mismo escenario que Madre de Dios.

\section{UNA RESPUESTA “GLOCAL” ANTE LA CRISIS AMBIENTAL}

Leyendo el libro "Secretos de la gente sana, cinco pasos para mejorar y conservar la salud" de Julio Basulto y María J. Mateo, encontré un término que llamó poderosamente mi atención, el "Glocal", que es definido por los autores como: "La frase nos insta a que tengamos en cuenta la salud del planeta en su conjunto (global) realizando pequeñas acciones en nuestras propias comunidades, en nuestro barrio y, sobre todo, en nuestro propio hogar (local)."

En buen cristiano, el término "Glocal" relaciona resultados con acciones, esto es, los grandes resultados no siempre serán producto de grandes acciones, sino que, en algunos casos, serán la suma de pequeñas acciones las que nos llevarán a esos grandes resultados.

Para entender este término podemos utilizar como ejemplo las campañas de siembra de árboles que las entidades impulsan en la ciudadanía. Cualquiera afirmaría que un árbol, en comparación con las existentes en la amazonia, no contribuye en gran medida, sin embargo, si esta siembra es replicada por los miembros de una localidad, y a su vez como un efecto multiplicador otra localidad se suma, y así sucesivamente, veremos que los resultados serán mejores que los deseados.

Quizás el lector no esté familiarizado con esas campañas, pero ¿qué pensaría sobre el uso de la bicicleta en reemplazo de unidades móviles que usan combustibles fósiles? Un auto Sedán emite 6 $\mathrm{kg}$. de $\mathrm{CO} 2$ en un trayecto de $10 \mathrm{~km}$. Ahora imagine si una empresa promoviera que sus ejecutivos reemplacen sus traslados en autos por bicicletas. Y, nuevamente, tenemos un efecto multiplicador, las emisiones de $\mathrm{CO} 2$ que dejan de ser expulsadas al ambiente serán ahora significativas en la lucha contra el cambio climático.

Hasta hace unos años el uso de las bicicletas era más recreacional. Pero, necesitamos de la aprobación de la Ley $\mathrm{N}^{\circ} 30936$ y de un contexto de pandemia, para contar con motivos para su uso con mayor frecuencia.

La realidad nos ha enseñado que en la lucha contra los temas que afectan el ambiente, nuestra casa, las pequeñas acciones son tan igual de importantes que las grandes. Somos conscientes de los problemas ambientales de nuestra localidad, y de la crisis climática que se vive a nivel mundial, pero necesitamos de normas que regulen nuestras conductas.

Enseñemos a nuestros hijos e hijas (aunque, ¿por qué esperar tanto?) y a quienes tengamos a nuestro alrededor que nuestras pequeñas acciones multiplicadas por $\mathrm{X}^{\mathrm{n}}$ pueden lograr grandes resultados.

Como señalan Basulto et.al (2012) en otro pasaje de su libro, "No es en absoluto recomendable descuidar lo que no tiene repuesto" (p.35) si bien hace referencia a la salud, creo que también aplica para nuestro planeta. 


\section{CONCLUSIONES}

1. En el país existen un sinfín de problemáticas ambientales, algunas más complicadas, otras de más larga data y otras tantas. Lo cierto es que debemos adoptar medidas. Planes de mediano y largo plazo son lujos que como sociedad no nos podemos dar. Estamos jugando una carrera a contrarreloj.

2. Más peligrosa que una verdad incómoda es una verdad cómoda, que nos hace creer que estamos yendo por el camino correcto, y que de seguir con este ritmo lograremos solucionar todas las problemáticas. Cuando queda claro que ello no será así.

3. Problemas como la presión demográfica, el asesinato de los defensores ambientales, el sobre consumo y nuestra deuda externa son solo algunos de los temas que se han visto por conveniente señalar. Si pretendiésemos escribir los otros tantos temas, podríamos tener una obra casi tan voluminosa como El Quijote, del Miguel de Cervantes Saavedra.

4. Como se señaló al inicio, y considero pertinente también terminar con ello. Ahora la sociedad viene luchando contra el Covid-19. Batalla de la cual poco a poco venimos saliendo. Ello debido a que hemos sido testigos de las vidas que en tan corto tiempo se ha llevado. Pero, si hacemos números, el cambio climático se puede haber llevado un número similar de vida. Entonces, qué más necesitamos para actuar a la altura de ello.

5. Como les señalé a mis alumnos, afirmamos que el hombre es un animal racional; sin embargo, el derecho ambiental nos ha demostrado lo tremendamente irracional que hemos sido, somos y que -lamentablemente- seguiremos siendo.

\section{REFERENCIAS}

- Andersen, I "No hay vacuna para el cambio climático" Programa de Naciones Unidas para el Medio Ambiente.https://www.bbc.com/mundo/noticias-55815999

- Basulto,j y Mateo, M. (2012). Secretos de la gente sana, cinco pasos para mejorar y conservar la salud Penguin Random House Grupo.

- Bauman, Z ¿La riqueza de unos pocos beneficia a todos?. Editorial Planeta Colombiana S.A.

- Bernex. N. (2009). Desafíos frente al problema ecológico en VI Jornada de Reflexión Ética Ética Ambiental y Política Pública. Fondo Editorial de la Universidad Antonio Ruiz de Montoya.

- Garrido Cordobera,L (2014) El riesgo ambiental.Editorial Ubijus.

- Organización de las Naciones Unidas ( 5 de julio de 2021) 13 deberes de los Estados sobre derechos humanos y biodiversidad.https://www.unep.org/es/noticias-y-reportajes/ reportajes/13-deberes-de-los-estados-sobre-derechos-humanos.

- Piperno D.Los habitantes de la Amazonía peruana vivieron "de manera sostenible" durante más de 5.000 años.https://www.bbc.com/mundo/noticias-57404958 